\title{
Molecular characterization of Blastocystis sp. in Chinese bamboo rats (Rhizomys sinensis)
}

\author{
Junke Song ${ }^{1, a}$, Xin Yang ${ }^{1, a}$, Xun $\mathrm{Ma}^{1, \mathrm{a}}$, Xuemei $\mathrm{Wu}^{1, \mathrm{a}}$, Yuxin Wang ${ }^{1, \mathrm{a}}$, Zhili $\mathrm{Li}^{2}$, Guohua Liu ${ }^{3}$, and Guanghui Zhao ${ }^{1, *}$ \\ ${ }^{1}$ College of Veterinary Medicine, Northwest A\&F University, Yangling 712100, Shaanxi, PR China \\ ${ }^{2}$ College of Life Science and Engineering, Foshan University, Foshan 528231, Guangdong, PR China \\ ${ }^{3}$ College of Veterinary Medicine, Hunan Agricultural University, Changsha 410125, Hunan, PR China
}

Received 11 June 2021, Accepted 26 November 2021, Published online 14 December 2021

\begin{abstract}
Blastocystis sp., a parasitic eukaryote, widely colonizes the intestines of humans and a large number of animals, including rodents and lagomorphs. More than 30 million bamboo rats (Rhizomys sinensis) are farmed in China as a source of meat for human consumption. However, there have been no published articles on Blastocystis infection in Chinese bamboo rats prior to the present study. Herein, 480 fresh faecal samples were collected from $R$. sinensis on six farms located in four cities (Wugang, Chenzhou, Huaihua and Jishou) in Hunan Province, south-central China, and were examined for Blastocystis infection using polymerase chain reaction (PCR) targeting the small subunit ribosomal RNA (SSU rRNA) gene. The total prevalence of Blastocystis in R. sinensis was 4.58\% (22/480), and significant differences in prevalence were detected among four age groups ( $<6$ months, 6-12 months, 12-24 months and $>24$ months), with the highest prevalence (7.81\%) in rats aged 6-12 months but with no positive samples in rats over 24 months. All farms, except for one in Jishou, were positive for Blastocystis infection, with the prevalence ranging from $1.80 \%$ to $7.27 \%$. Sequence and phylogenetic analyses revealed two potentially zoonotic subtypes (namely ST4 and ST5) in these rodents, with ST4 predominant in all except one farm in Huaihua. Seven and five sequence types were identified within ST4 and ST5, respectively. This is the first report of Blastocystis infection in Chinese bamboo rats and the findings suggest the potential of $R$. sinensis to transmit Blastocystis to humans.
\end{abstract}

Key words: Blastocystis sp., Prevalence, Subtyping, Rhizomys sinensis, Hunan Province.

Résumé - Caractérisation moléculaire de Blastocystis sp. chez le rat des bambous chinois (Rhizomys sinensis). Blastocystis sp., un parasite eucaryote, colonise largement les intestins de l'homme et d'un grand nombre d'animaux dont les rongeurs et les lagomorphes. Plus de 30 millions de rats des bambou (Rhizomys sinensis) sont élevés en Chine comme source de viande pour la consommation humaine. Cependant, il n'y a eu aucun article publié sur l'infection à Blastocystis chez les rats des bambou chinois avant la présente étude. Ici, 480 échantillons de matières fécales fraîches ont été prélevés sur $R$. sinensis dans six fermes situées dans quatre villes (Wugang, Chenzhou, Huaihua et Jishou) de la province du Hunan, dans le centre-sud de la Chine, et ont été examinés pour une infection à Blastocystis en utilisant la réaction en chaîne par polymérase (PCR) ciblant le gène de l'ARN ribosomique de la petite sous-unité (ARNr SSU). La prévalence totale de Blastocystis chez $R$. sinensis était de 4,58\% (22/480), et des différences significatives de prévalence ont été détectées parmi quatre groupes d'âge ( $<6$ mois, 6-12 mois, 12-24 mois et $>24$ mois), avec la prévalence la plus élevée $(7,81 \%)$ chez les rats âgés de 6 à 12 mois mais sans échantillon positif chez les rats de plus de 24 mois. Toutes les fermes, à l'exception d'une à Jishou, étaient positives pour l'infection à Blastocystis, avec une prévalence allant de $1,80 \%$ à $7,27 \%$. Les analyses de séquences et phylogénétiques ont révélé deux sous-types potentiellement zoonotiques (à savoir ST4 et ST5) chez ces rongeurs, ST4 prédominant dans toutes les exploitations sauf une à Huaihua. Sept et cinq types de séquences ont été identifiés parmi ST4 et ST5, respectivement. Il s'agit du premier rapport d'infection à Blastocystis chez des rats des bambou chinois et les résultats suggèrent le potentiel de $R$. sinensis à transmettre Blastocystis à l'homme.

\section{Introduction}

Blastocystis sp., a common parasitic eukaryote, inhabits the intestines of humans and a large number of animals throughout

*Corresponding author: zgh083@163.com

${ }^{\mathrm{a}}$ Equal contribution. the world [13, 30]. More than one billion people are estimated to be infected with Blastocystis globally, and the colonization rate of Blastocystis sp. in livestock ranges from $5.5 \%$ to $87.1 \%[6,7,13,26,28]$. However, there are still controversies around the pathogenic potential of Blastocystis. Recently, Blastocystis sp. was suggested as an indicator for 
Table 1. Factors associated with prevalence of Blastocystis infection in Rhizomys sinensis in Hunan Province.

\begin{tabular}{|c|c|c|c|c|c|}
\hline Factor & Category & & No. examined & No. positive (\%) & Subtypes (No.) \\
\hline \multicolumn{6}{|l|}{$\overline{\text { Age }}$} \\
\hline & 0-6 months & & 136 & $8(5.88)$ & ST4 (6), ST5 (2) \\
\hline & $>6-12$ months & & 128 & $10(7.81)$ & ST4 (7), ST5 (3) \\
\hline & $>12-24$ months & & 151 & $4(2.65)$ & ST4 (4) \\
\hline & $>24$ months & & 65 & 0 & 0 \\
\hline \multicolumn{6}{|l|}{ Location } \\
\hline & Wugang city & Farm 1 & 207 & $12(5.80)$ & ST4 (12) \\
\hline & & Farm 2 & 66 & $3(4.55)$ & ST4 (1), ST5 (2) \\
\hline & & Farm 3 & 55 & $4(7.27)$ & ST4 (3), ST5 (1) \\
\hline & Chenzhou city & Farm 4 & 111 & $2(1.80)$ & ST4 (1), ST5 (1) \\
\hline & Huaihua city & Farm 5 & 26 & $1(3.85)$ & ST5 (1) \\
\hline & Jishou city & Farm 6 & 15 & 0 & 0 \\
\hline Total & & & 480 & $22(4.58)$ & ST4 (17), ST5 (5) \\
\hline
\end{tabular}

the intestinal health of animals and humans, suggesting a new public health perspective on this protist $[5,9,15,18,27]$.

The Chinese bamboo rat (Rhizomys sinensis) is a species of rodent belonging to the subfamily Rhizomyinae that originally inhabited mountainous areas of Asia, e.g. southern China, Myanmar and Vietnam [24]. Because of good nutritional properties (especially high crude protein, low fat and cholesterol) and medical value, this animal has been farmed since the 1990s as a source of meat in southern China [10]. In 2011, the number of farmed $R$. sinensis was more than 30 million in China, mainly distributed in the Guangxi, Hunan, Guangdong, Jiangxi and Zhejiang Provinces of China [10, 24, 29]. However, due to changes in living conditions and food sources, the resistance of $R$. sinensis to various pathogens is decreasing. In recent decades, several pathogens (e.g. Escherichia coli, Cryptosporidium, Penicillium marneffei, Giardia duodenalis, Trichinella spiralis) have been detected in $R$. sinensis. Some zoonotic pathogens (e.g. E. coli, P. marneffei, G. duodenalis, Cryptosporidium and T. spiralis) in these animals also have important implications for human health [3, 11, 12, 29].

Although Blastocystis sp. has not been reported in $R$. sinensis, it has been detected in several species of rodents, with a prevalence of 3-100\% [8]. Furthermore, of 32 known subtypes, 11 (including potentially zoonotic ST1-ST5, ST7 and ST8, and animal-adapted ST10, ST13, ST15 and ST17) have been reported in captive and wild rodents [8]. In order to understand the infection status of Blastocystis sp. in $R$. sinensis, the present study investigated the prevalence and subtypes of Blastocystis sp. in R. sinensis from Hunan Province and assessed the potentially zoonotic risk of these animals.

\section{Materials and methods}

\section{Ethics statement}

This study was approved by the Research Ethics Committee of Northwest A\&F University, Research Ethics Committee of Foshan university, and the Guidance of Laboratory Animal Care and Use of Chinese Ministry of Health, China. All samplings were permitted by farmers and no bamboo rats were hurt during sampling.

\section{Specimens, DNA extraction and PCR amplification}

The faecal and DNA samples have already been described [12]. To determine the prevalence of Blastocystis sp. in these samples, each genomic DNA sample was amplified by PCR targeting the small sub-unit ribosomal RNA (SSU rRNA) gene with the universal Blastocystis primers (BhRDr and RD5) described previously [19]. The PCR products were analysed using $1 \%$ agarose gels electrophoresis, and stained with ethidium bromide, and the positive products were sent to Sangon Biotech (Shanghai) Co., Ltd. for direct sequencing in both directions using the PCR primers.

\section{Sequence and phylogenetic analysis}

The sequences obtained were aligned with the reference sequences of Blastocystis sp. available in GenBank using the Basic Local Alignment Search Tool (BLAST) from the US National Center for Biotechnology Information (NCBI). All sequences and alignment results were re-checked and manually corrected by eye. Representative sequences for each sequence type were then used for phylogenetic analysis to determine subtypes of Blastocystis sp. The neighbour-joining (NJ) method within software MEGA 6.06 [23] was used to construct the genetic tree, with the Kimura 2-parameter model and bootstrap analysis (1000 replications).

\section{Statistical analysis}

A $\chi^{2}$ test was used to analyse the differences in prevalence among different age groups and regions using SPSS 19.0 software for Windows (SPSS Inc., Chicago, IL, USA). The difference was considered significant when $p<0.05$.

\section{Nucleotide sequence accession numbers}

Representative nucleotide sequences in the present study have been submitted to GenBank under the accession numbers MK789174-MK789180 and MK789278-MK789282. 


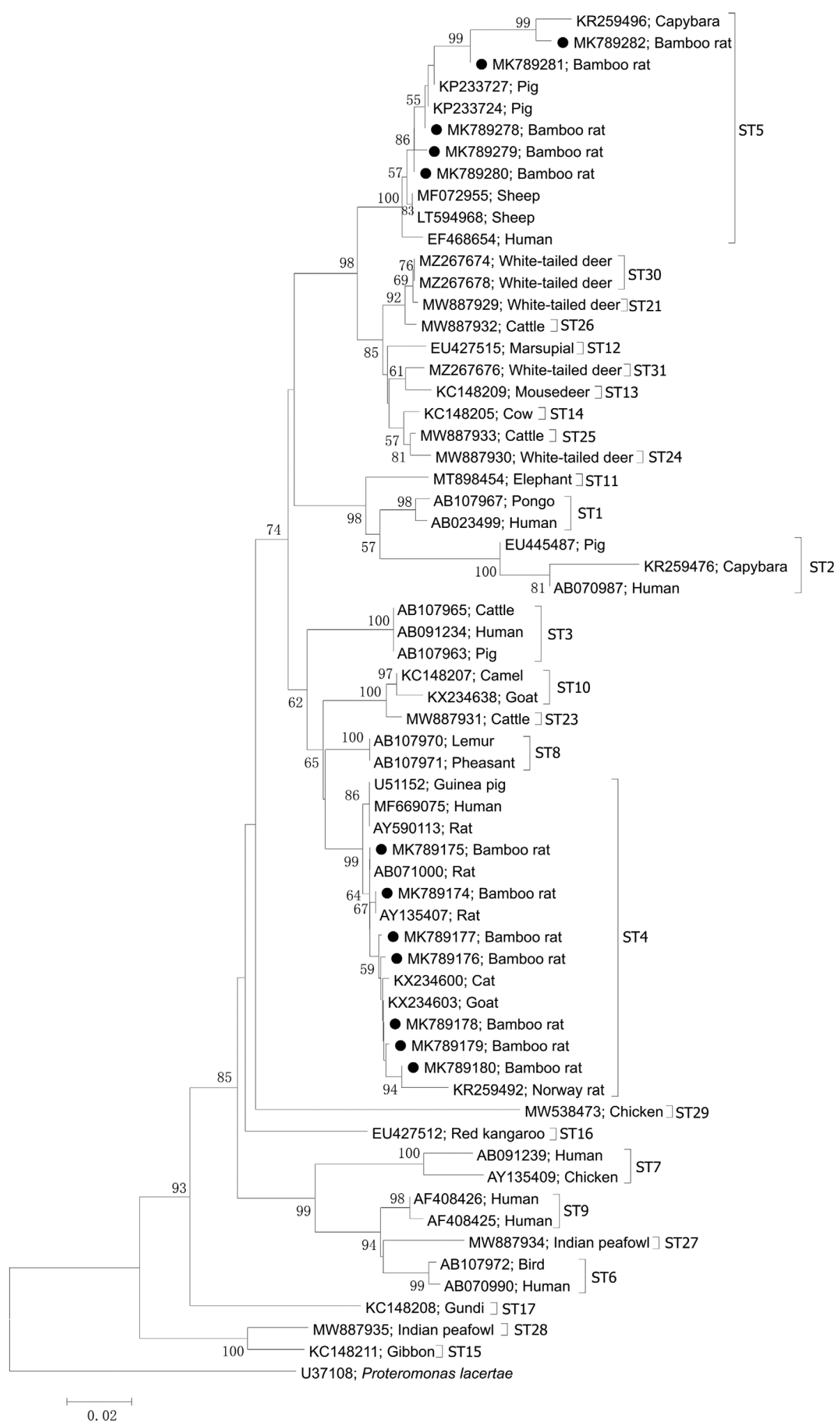

Figure 1. Phylogenetic analysis of Blastocystis subtypes in the present study (black filled circles before the accession number) with reference sequence from GenBank based on the SSU rRNA gene fragment by the neighbour-joining method using the Kimura 2-parameter model. Bootstrap values $(>50)$ are indicated at the nodes. Scale bar indicates 0.02 nucleotide substitutions/site. Proteromonas lacertae (U37108) is used as the outgroup. 


\section{Results and discussion}

Blastocystis sp. has been reported in rodents in Europe, Asia, Africa and the Americas, including brown rats, house rats, bank vole, chinchilla, yellow necked mouse, wood mouse, gundi, Norway rats, capybara and squirrels, with prevalence ranging from $3 \%$ to $100 \%$ [8]. However, there are still no data on the occurrence of Blastocystis sp. in $R$. sinensis. In the present study, Blastocystis infection was investigated in $R$. sinensis for the first time by applying the PCR-sequencing technique based on the SSU rRNA gene. The overall prevalence of Blastocystis sp. in R. sinensis was $4.58 \%$ (22/48), which is higher than in brown rats $(3.7 \%)$, spontaneous hypertensive rats (3\%) and chinchilla (4.2\%) from China, and bank vole (3.1\%) from the United Kingdom, but is lower than in most rodents reported previously [8]. The differences in prevalence may be due to sampling numbers, detection procedures and different susceptibilities of rodents to Blastocystis. For example, only five studies examined over 100 samples of rodents, while no more than 100 or even fewer than 10 faecal samples were examined in other previous studies [8]. Furthermore, the differences in Blastocystis prevalence were observed among the six farms from four geographical origins in our study, with the highest prevalence $(7.27 \%)$ on Farm 3 in Wugang city, and no positive samples were detected on Farm 6 in Jizhou city, but with no significant differences $\left(\chi^{2}=4.324, d f=5\right.$, $p>0.05$ ) among these farms (Table 1).

In the present study, significant differences $\left(\chi^{2}=7.991\right.$, $d f=3, p<0.05)$ in Blastocystis prevalence were detected in $R$. sinensis among four age groups ( $<6$ months, 6-12 months, 12-24 months and >24 months) (Table 1), with the highest prevalence $(7.81 \%)$ in rats aged of 6-12 months, but with no findings of any Blastocystis-positive faecal sample in rodents over 24 months. Additionally, although the prevalence in $R$. sinensis was slightly lower than that in rats 6-12 months, it seemed that the prevalence deceased with the age. This similar trend was also observed in several previous reports from humans where Blastocystis prevalence in children was higher than that in adults, suggesting high susceptibility of young individuals to Blastocystis infection [16, 20].

Currently, genetic analysis revealed at least 32 known Blastocystis STs in mammals, birds and humans. Sequence and phylogenetic analyses revealed two potentially zoonotic subtypes in $R$. sinensis in the present study (Fig. 1), namely ST4 and ST5. Seven sequence types were identified within ST4, including MK789174 (1), MK789175 (4), MK789176 (1), MK789177 (1), MK789178 (7), MK789179 (2) and MK789180 (1), while five sequence types were found within ST5, including MK789278 (1), MK789279 (1), MK789280 (1), MK789281 (1) and MK789282 (1). ST4 was the predominant subtype found in all positive age groups and sampled farms, except Farm 5 in Huaihua city. Interestingly, ST4 was also identified as being prevalent in other rodents, e.g. brown rats, Norway rats and Polynesian rats [4, 25, 28], suggesting the importance of this subtype for controlling Blastocystis infection in rodents. It is notable that two ST4 sequences (MK789177 and MK789178) in the present study were identical to sequences from humans (JN682513 and MH197686) in GenBank, reflecting the potential transmission of ST4 between humans and bamboo rats in this study. Additionally, the ST4 sequences (MK789174, MK789176 and MK789177) in this study were also identical to sequences from other rodents, such as chinchillas (MN124750), Edwards's long-tailed giant rat (Leopoldamys edwardsi) (MT302172) and Chinese hamsters (MN736534) reported in GenBank. ST5 was only found in $R$. sinensis aged less than one year, but it was noted that the ST5 was widely found on four positive farms. This subtype has also been detected in cattle, pigs, chimpanzees, gorillas, gibbons, roe deer, black rhinoceros, goats, camels, ostriches and humans [1, 2, 4, 14, 17, 21, 22, 30]. Interestingly, two ST5 sequences (MK789278 and MK789280) in this study were identical to sequences from pigs (MT373853 and MN493734) in GenBank. Considering the zoonotic potential of these two subtypes, the potential of $R$. sinensis for transmitting Blastocystis sp. to humans should be further evaluated.

\section{Conclusions}

The present study revealed the occurrence of Blastocystis infection in $R$. sinensis, with an overall prevalence of $4.58 \%$. Phylogenetic analysis identified two potentially zoonotic subtypes in these rodents. This study expanded the host range of Blastocystis sp. and provided baseline data for prevention and control of Blastocystis sp. in R. sinensis.

Acknowledgements. We thank Prof. Xing-Quan Zhu from Lanzhou Veterinary Research Institute, Chinese Academy of Agricultural Sciences, for assistance in improvement of the language of this article.

\section{Conflicts of interest}

The authors declare that they have no conflict of interest.

\section{References}

1. Alfellani MA, Taner-Mulla D, Jacob AS, Imeede CA, Yoshikawa H, Stensvold CR, Clark CG. 2013. Genetic diversity of Blastocystis in livestock and zoo animals. Protist, 164(4), 497-509.

2. Badparva E, Sadraee J, Kheirandish F. 2015. Genetic diversity of Blastocystis isolated from cattle in Khorramabad, Iran. Jundishapur Journal of Microbiology, 8(3), e14810.

3. Chariyalertsak S, Vanittanakom P, Nelson KE, Sirisanthana T, Vanittanakom N. 1996. Rhizomys sumatrensis and Cannomys badius, new natural animal hosts of Penicillium marneffei. Journal of Medical and Veterinary Mycology, 34(2), 105-110.

4. Cian A, Safadi DE, Osman M, Moriniere R, Gantois N, Benamrouz-Vanneste S, Delgado-Viscogliosi P, Guyot K, Li LL, Monchy S, Noel C, Poirier P, Nourrisson C, Wawrzyniak I, Delbac F, Bosc S, Chabe M, Petit T, Certad G. 2017. Molecular epidemiology of Blastocystis sp. in various animal groups from two French zoos and evaluation of potential zoonotic risk. PLoS One, 12(1), e0169659.

5. Collins SM. 2014. A role for the gut microbiota in IBS. Nature Reviews Gastroenterology \& Hepatology, 11(8), 497-505.

6. Deng L, Chai Y, Zhou Z, Liu H, Zhong Z, Hu Y, Fu H, Yue C, Peng G. 2019. Epidemiology of Blastocystis sp. infection in China: a systematic review. Parasite, 26, 41. 
7. Greige S, Safadi D, Becu N, Gantois N, Pereira B, Chabé M, Benamrouz-Vanneste S, Certad G, Hage RE, Chemaly M, Hamze M, Viscogliosi E. 2018. Prevalence and subtype distribution of Blastocystis sp. isolates from poultry in Lebanon and evidence of zoonotic potential. Parasites \& Vectors, 11, 389.

8. Hublin JSY, Maloney JG, Santin M. 2021. Blastocystis in domesticated and wild mammals and birds. Research in Veterinary Science, 135, 260-282.

9. Kurt Ö, Doğruman Al F, Tanyüksel M. 2016. Eradication of Blastocystis in humans: really necessary for all? Parasitology International, 65(6PtB), 797-801.

10. Liu J, Tang CH, Zhou DC, Zeng QB. 2011. Current situation and countermeasures of bamboo rat in China. Journal of Hunan Vocational College of Environmental Biology, 17(2), 1-5. (in Chinese).

11. Liu X, Zhou X, Zhong Z, Zuo Z, Shi J, Wang Y, Qing B, Peng G. 2015. Occurrence of novel and rare subtype families of Cryptosporidium in bamboo rats (Rhizomys sinensis) in China. Veterinary Parasitology, 207(1-2), 144-148.

12. Ma X, Wang Y, Zhang HJ, Wu HX, Zhao GH. 2018. First report of Giardia duodenalis infection in bamboo rats. Parasites \& Vectors, 11, 520.

13. Paulos S, Koster PC, Lucio A, Hernandez-de-Mingo M, Cardona GA, Fernandez-Crespo JC, Stensvold CR, Carmena D. 2018. Occurrence and subtype distribution of Blastocystis sp. in humans, dogs and cats sharing household in northern Spain and assessment of zoonotic transmission risk. Zoonoses and Public Health, 65(8), 993-1002.

14. Pintong AR, Sunyanusin S, Prasertbun R, Mahittikorn A, Mori $\mathrm{H}$, Changbunjong T, Komalamisra C, Sukthana Y, Popruk S. 2018. Blastocystis subtype 5: Predominant subtype on pig farms, Thailand. Parasitology International, 67(6), 824-828.

15. Poirier P, Wawrzyniak I, Vivarès CP, Delbac F, El Alaoui H. 2012. New insights into Blastocystis spp.: a potential link with irritable bowel syndrome. PLoS Pathogens, 8(3), e1002545.

16. Poulsen CS, Efunshile AM, Nelson JA, Stensvold CR. 2016. Epidemiological aspects of Blastocystis colonization in children in Ilero, Nigeria. American Journal of Tropical Medicine and Hygiene, 95(1), 175-179.

17. Ramírez JD, Sanchez A, Hernandez C, Flórez C, Bernal MC, Giraldo JC, Reyes P, López MC, García L, Cooper PJ, Vicuña Y, Mongi F, Casero RD. 2016. Geographic distribution of human Blastocystis subtypes in South America. Infection, Genetics and Evolution, 41, 32-35.

18. Sánchez A, Munoz M, Gómez N, Tabares J, Segura L, Salazar Á, Restrepo C, Ruíz M, Reyes P, Qian Y, Xiao L, López MC, Ramírez JD. 2017. Molecular epidemiology of Giardia, Blastocystis and Cryptosporidium among indigenous children from the Colombian Amazon Basin. Frontiers in Microbiology, 8, 248.

19. Scicluna SM, Tawari B, Clark CG. 2006. DNA barcoding of Blastocystis. Protist, 157(1), 77-85.
20. Seguí R, Muñoz-Antoli C, Klisiowicz DR, Oishi CY, Köster PC, Lucio A, Hernández-de-Mingo M, Puente P, Toledo R, Esteban JG, Carmena D. 2018. Prevalence of intestinal parasites, with emphasis on the molecular epidemiology of Giardia duodenalis and Blastocystis sp., in the Paranaguá Bay, Brazil: a community survey. Parasites \& Vectors, 11, 490.

21. Song JK, Yin YL, Yuan YJ, Tang H, Ren GJ, Zhang HJ, Li ZX, Zhang YM, Zhao GH. 2017. First genotyping of Blastocystis sp. in dairy, meat, and cashmere goats in northwestern China. Acta Tropica, 176, 277-282.

22. Stensvold CR, Alfellani MA, Nørskov-Lauritsen S, Prip K, Victory EL, Maddox C, Nielsen HV, Clark CG. 2009. Subtype distribution of Blastocystis isolates from synanthropic and zoo animals and identification of a new subtype. International Journal for Parasitology, 39(4), 473-479.

23. Tamura K, Peterson D, Peterson N, Stecher G, Nei M, Kumar S. 2011. MEGA5: molecular evolutionary genetics analysis using maximum likelihood, evolutionary distance, and maximum parsimony methods. Molecular Biology and Evolution, 28(10), 2731-2739.

24. Tang HB, Chen F, Rao G, Bai A, Jiang J, Du Y, Ren P, Liu J, Qin S, Yang L, Wu J. 2017. Characterization of Akabane virus from domestic bamboo rat, Southern China. Veterinary Microbiology, 207, 280-285.

25. Wang J, Gong B, Liu X, Zhao W, Bu T, Zhang W, Liu A, Yang F. 2018. Distribution and genetic diversity of Blastocystis subtypes in various mammal and bird species in northeastern China. Parasites \& Vectors, 11, 522.

26. Wang J, Gong B, Yang F, Zhang W, Zheng Y, Liu A. 2018b. Subtype distribution and genetic characterizations of Blastocystis in pigs, cattle, sheep and goats in northeastern China's Heilongjiang Province. Infection, Genetics and Evolution, 57, 171-176.

27. Yakoob J, Jafri W, Jafri N, Khan R, Islam M, Beg MA, Zaman V. 2004. Irritable bowel syndrome: in search of an etiology: role of Blastocystis hominis. American Journal of Tropical Medicine and Hygiene, 70(4), 383-385.

28. Yoshikawa H, Tokoro M, Nagamoto T, Arayama S, Asih PBS, Rozi IE, Syafruddin D. 2016. Molecular survey of Blastocystis sp. from humans and associated animals in an Indonesian community with poor hygiene. Parasitology International, 65 (6PtB), 780-784.

29. Zhang H, Li K, Wang Y, Rehman MU, Liu Y, Jin J, Peng J, Nabi F, Mehmood K, Luo H, Wang J. 2017. Investigation and characterization of $\beta$-lactam resistance in Escherichia coli strains isolated from bamboo rats (Rhizomys sinensis) in Zhejiang province, China. Journal of Veterinary Medical Science, 79(10), 1633-1636.

30. Zhao GH, Hu XF, Liu TL, Hu RS, Yu ZQ, Yang WB, Wu YL, Yu SK, Song JK. 2017. Molecular characterization of Blastocystis sp. in captive wild animals in Qinling Mountains. Parasitology Research, 116(8), 2327-2333. 
An international open-access, peer-reviewed, online journal publishing high quality papers on all aspects of human and animal parasitology

Reviews, articles and short notes may be submitted. Fields include, but are not limited to: general, medical and veterinary parasitology; morphology, including ultrastructure; parasite systematics, including entomology, acarology, helminthology and protistology, and molecular analyses; molecular biology and biochemistry; immunology of parasitic diseases; host-parasite relationships; ecology and life history of parasites; epidemiology; therapeutics; new diagnostic tools.

All papers in Parasite are published in English. Manuscripts should have a broad interest and must not have been published or submitted elsewhere. No limit is imposed on the length of manuscripts.

Parasite (open-access) continues Parasite (print and online editions, 1994-2012) and Annales de Parasitologie Humaine et Comparée (1923-1993) and is the official journal of the Société Française de Parasitologie. 